\title{
Adaptive Quantum Computation in Changing Environments Using a Multi-Mimotopic Algorithmic Approach for Biclustering Analysis of Expression Data Projective Simulation on an Anticancer Peptide SVS-1 Multipharmacophore as a Potential Drug-Like Efficator in Preceding Membrane Neutralization
}

\author{
Ioannis $\mathrm{G}^{1}$, George $\mathrm{G}^{2}$ and Nikolaos $\mathrm{SG}^{3 *}$ \\ ${ }^{1}$ Department of Computer Drug Discovery Science, BiogenetoligandorolTM, Greece \\ ${ }^{2}$ Department of Stem Cell Bank and ViroGenea TM, Biogenea Pharmaceuticals Ltd, Greece \\ ${ }^{3}$ Department of ITS Computer Aided Personalized Myoncotherapy, Cordigenea-HyperoligandorolTM, Greece
}

Submission: September 09, 2017; Published: September 22, 2017

*Corresponding author: Nikolaos G, Department of ITS Computer Aided Personalized Myoncotherapy, Cartigenea-Cardiogenea, NeurogeneaCellgenea, Cordigenea-HyperoligandorolTM, Greece, Email: biogeneadrug@gmail.com

\begin{abstract}
Anticancer peptides (ACPs) are polycationic amphiphiles capable of preferentially killing a wide spectrum of cancer cells relative to noncancerous cells. Their primary mode of action is an interaction with the cell membrane and subsequent activation of lyric effects however it remains controversial the exact mechanism responsible for this mode of action. It has in previous studies been shown that utilizing zeta potential analyses it was possible to demonstrate the interaction of a small anticancer peptide with membrane model systems and cancer cells. Electrostatic interactions have a pivotal role in the cell killing process and in contrast to the AMPs action cell death occurs without achieving full neutralization of the membrane charge. The advent of microarray technology has revolutionized the search for genes that are differentially expressed across a range of cell types or experimental conditions. Traditional clustering methods, such as hierarchical clustering, are often difficult to deploy effectively since genes rarely exhibit similar expression pattern across a wide range of conditions. Web-enabled service called GEMS (Gene Expression Mining Server) for bolstering microarray data where Users may upload expression data and specify a set of criteria. GEMS perform baluster mining based on a Gibbs sampling paradigm.
\end{abstract}

Keywords: Adaptive quantum computation; Environments; Projective simulation; In silica; Anticancer peptide; SVS-1; Multipharmacophore; Drug-like; Efficator; Preceding membrane; Neutralization; Web server; Multi isotopic; Algorithmic; Biclustering analysis; Expression data

\section{Mini Review}

Biogenea we have for the first time discovered an Anticancer Peptide SVS-1 Multipharmacophore with an in silicon evaluated Efficacy in Preceding Membrane Neutralization using a web server for bolstering analysis of expression data. Quantum information processing devices need to be robust and stable against external noise and internal imperfections to ensure correct operation. In a setting of measurement-based quantum computation, we explore how an intelligent agent endowed with a projective simulator can act as controller to adapt measurement directions to an external stray field of unknown magnitude in a fixed direction. We assess the agent's learning behavior in static and time-varying fields and explore composition strategies in the projective simulator to improve the agent's performance. We demonstrate the applicability by correcting for stray fields in a measurement-based algorithm for Grover's search. There by we lay out a path for adaptive controllers based on intelligent agents for quantum information tasks. When building devices for quantum information processing one has to take changing environment conditions and device imperfections into account. It is therefore necessary to include adaptive mechanisms that characterize and calibrate the device from 
within. Furthermore it is desirable for these devices to obtain a certain degree of autonomy in maintaining their functional state despite detrimental environment influences, in particular, when they are assembled to a larger quantum information processing infrastructure. In the attempt to miniaturize current implementations of quantum devices, we will reach the point where these devices will be of microscopic scale and require short reaction times. For such microscopic systems we can no longer assume that their internal controllers are full-fledged universal computers that can carry out arbitrary programs.
Instead controllers will be small physical systems that are specialized for their respective purpose with a program that emerges from the controller's analog dynamics. In this paper we explore the applicability of a controller in form of an intelligent learning agent that has access to a projective adaptive quantum commutated simulator in changing environments using a multi-isotopic algorithmic approach for bolstering analysis of expression data projective simulation on an Anticancer Peptide SVS-1 Multipharmacophore as a potential drug-like defecator in Preceding Membrane Neutralization.

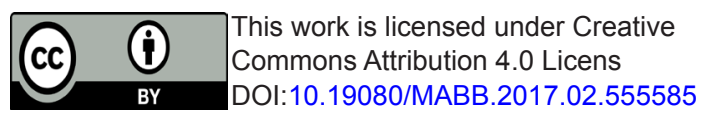

\section{Your next submission with Juniper Publishers will reach you the below assets}

- Quality Editorial service

- Swift Peer Review

- Reprints availability

- E-prints Service

- Manuscript Podcast for convenient understanding

- Global attainment for your research

- Manuscript accessibility in different formats

( Pdf, E-pub, Full Text, Audio)

- Unceasing customer service

Track the below URL for one-step submission https://juniperpublishers.com/online-submission.php 